\title{
Os desafios da universidade pública pós-pandemia da Covid-19: o caso brasileiro
}

Lourdes Maria Rodrigues Cavalcanti a Maria das Graças Gonçalves Vieira Guerra ${ }^{b}$

\section{Resumo}

O objetivo desse artigo é refletir sobre os desafios da universidade pública pós-pandemia da Covid-19, a partir dos dados disponibilizados pelo Portal do Ministério da Educação do Brasil. Utilizou-se uma metodologia de caráter exploratório, com abordagem qualitativa e estratégia bibliográfico-documental. Constatou-se que o perfil de universidade pública que emergiu dos dados sugere a necessidade de uma mudança no modelo institucional e organizacional, que atualmente acomoda a universidade. Impõe-se que a universidade se reinvente, que se transforme em uma nova instituição, dotada de modelos de gestão atuais, flexíveis e que favoreçam ajustes, posto que tais funcionalidades são mais adequadas à dinâmica organizacional e à gestão de riscos.

Palavras-chave: Portal MEC/Coronavírus. Pandemia. Universidade Pública.

\section{Introdução}

No início do mês de fevereiro de 2020, o mundo tomou conhecimento, estarrecido, da existência do vírus da Covid-19, originário da cidade de Wuhan, na China, no mês de dezembro de 2019, tornando-se, posteriormente, uma pandemia, a primeira calamidade do século XXI, afetando, em nível mundial, a economia, os sistemas de saúde e a vida das pessoas (OLIVEIRA; GOMES; BARCELLOS, 2020).

As Nações contabilizam os prejuízos econômicos, desde então, e, hoje, se tem a exata noção dos estragos causados pela Covid-19, cuja letalidade trouxe à tona a fragilidade da vida humana, alterando, em nível planetário, para sempre, as rotinas familiares, sanitárias, econômicas, educacionais e de deslocamento, sejam de que forma for.

\footnotetext{
a Universidade Federal da Paraíba, João Pessoa, PB, Brasil.

b Universidade Federal da Paraíba, João Pessoa, PB, Brasil. 
No Brasil, para além da crise sanitária causada pelo novo coronavírus, viu-se que falta ao nosso país um projeto de nação, e, o que é mais preocupante, é que ficou evidente que o planejamento governamental, em todas as esferas do poder público, deixa a desejar, quando existe.

Em relação à Educação, vários fatores contribuíram para o agravamento da situação, em relação às Universidades Federais (IFES), objeto de nossa pesquisa, pois foi constatado que, mesmo dispondo de uma ferramenta de planejamento institucional, em vigor há mais de 15 anos - que é o Plano de Desenvolvimento Institucional (PDI) - não foi detectada a existência de um plano de contingência que fosse capaz de lidar com a crise causada pela pandemia, nem nas Universidades Federais, nem no Ministério da Educação (MEC), que, até o momento, sequer dispõe de um Gabinete de Gestão da Crise causada pela Covid-19, que possa orientar as universidades públicas, por meio de procedimentos e de rotinas padronizadas. Ressaltam, Cavalcanti e Guerra (2019, p. 704), que

O PDI é um instrumento de planejamento e gestão, que estabelece a identidade da IES, levando em consideração sua filosofia de trabalho, a missão e as estratégias para atingir as metas e objetivos planejados. Abrange, também, os aspectos da estrutura organizacional e do Projeto Pedagógico Institucional, buscando a observância das diretrizes pedagógicas que orientam as ações, atividades acadêmicas e científicas que já desenvolve, ou planeja desenvolver.

Foi a partir do mês de março de 2020, que o Estado brasileiro tomou medidas em relação ao sistema federal de Ensino para o enfrentamento do problema, tendo como ato primeiro, a emissão da Portaria MEC n ${ }^{\circ} 343$, de 17 de março de 2020 (BRASIL, 2020a). Esquematizaram-se, no Quadro 1, as normativas emitidas pela União, com vistas ao enfrentamento da pandemia da Covid-19, no âmbito do Ensino Superior.

Quadro 1 - Atos legais do Estado Brasileiro para o enfrentamento à Covid-19

\begin{tabular}{|l|l|}
\hline ATO & \multicolumn{1}{c|}{ EMENTA } \\
\hline $\begin{array}{l}\text { Portaria no 188, de 03 de fevereiro de 2020 } \\
\text { Publicada no Diário Oficial da União (DOU) } \\
\text { de 04/02/2020 }\end{array}$ & $\begin{array}{l}\text { Declara Emergência em Saúde Pública de } \\
\text { importância Nacional (Espin) em decorrência } \\
\text { da Infecção Humana pelo novo coronavírus } \\
(2019-n C o V) .\end{array}$ \\
\hline $\begin{array}{l}\text { Lei } \mathbf{n}^{\circ} \mathbf{1 3 . 9 7 9} \text { de } \mathbf{0 6} \text { de fevereiro de } \mathbf{2 0 2 0} \\
\text { Publicada no DOU de 07/02/2020 }\end{array}$ & $\begin{array}{l}\text { Dispõe sobre as medidas para enfrentamento } \\
\text { da emergência de saúde pública de } \\
\text { importância internacional decorrente do novo } \\
\text { coronavírus, responsável pelo surto de 2019. }\end{array}$ \\
\hline
\end{tabular}


Continuação

\begin{tabular}{|c|c|}
\hline ATO & EMENTA \\
\hline $\begin{array}{l}\text { Portaria } \mathbf{n}^{\circ} \mathbf{3 5 6} \text {, de } \mathbf{1 1} \text { de fevereiro de } 2020 \\
\text { Publicada no DOU de } 12 / 02 / 2020\end{array}$ & $\begin{array}{l}\text { Dispõe sobre a regulamentação e } \\
\text { operacionalização do disposto na Lei no } \\
13.979, \text { de } 6 \text { de fevereiro de } 2020 \text {, que } \\
\text { estabelece as medidas para enfrentamento } \\
\text { da emergência de saúde pública de } \\
\text { importância internacional, decorrente do } \\
\text { novo coronavírus (Covid-19). }\end{array}$ \\
\hline $\begin{array}{l}\text { Portaria } \mathbf{n}^{\circ} \mathbf{3 4 3} \text {, de } 17 \text { de março de } 2020 \\
\text { Publicada no DOU de 18/03/2020 }\end{array}$ & $\begin{array}{l}\text { Dispõe sobre a substituição das aulas } \\
\text { presenciais por aulas em meios digitais } \\
\text { enquanto durar a situação de pandemia do } \\
\text { novo coronavírus (Covid-19). }\end{array}$ \\
\hline $\begin{array}{l}\text { Portaria } \mathbf{n}^{\circ} \mathbf{6 8 3} \text {, de } 19 \text { de março de } 2020 \\
\text { Publicada no DOU de } 20 / 03 / 2020\end{array}$ & $\begin{array}{l}\text { Dispõe sobre a instituição do comitê } \\
\text { técnico para elaboração de iniciativas de } \\
\text { promoção e de defesa dos Direitos Humanos, } \\
\text { considerando a situação de emergência de } \\
\text { saúde pública de importância internacional, } \\
\text { decorrente do novo coronavírus (Covid-19). }\end{array}$ \\
\hline $\begin{array}{l}\text { Decreto Legislativo } \mathbf{n}^{\mathbf{0}} \mathbf{6} \text {, de } \mathbf{2 0} \text { de março } \\
\text { de } 2020 \\
\text { Publicado no DOU de } 20 / 03 / 2020\end{array}$ & $\begin{array}{l}\text { Reconhece, para os fins do art.65 da Lei } \\
\text { Complementar no } 101 \text {, de } 4 \text { de maio de } 2000 \text {, } \\
\text { a ocorrência do estado de calamidade pública, } \\
\text { nos termos da solicitação do Presidente } \\
\text { da República, encaminhada por meio da } \\
\text { Mensagem } n^{\circ} 93 \text {, de } 18 \text { de março de } 2020 \text {. }\end{array}$ \\
\hline $\begin{array}{l}\text { Portaria } \mathbf{n}^{\circ} \mathbf{4 5 4} \text {, de } \mathbf{2 0} \text { de março de } 2020 \\
\text { Publicada no DOU de } 20 / 03 / 2020 \text { - edição } \\
\text { extra-F }\end{array}$ & $\begin{array}{l}\text { Declara, em todo o território nacional, o } \\
\text { estado de transmissão do novo coronavírus } \\
\text { (Covid-19). }\end{array}$ \\
\hline $\begin{array}{l}\text { Decreto } \text { no }^{\circ} \mathbf{1 0 . 2 8 2} \text {, de } 20 \text { de março de } 2020 \\
\text { Publicado no DOU de } 20 / 03 / 2020 \text { - edição } \\
\text { extra-G e } \\
\text { Republicado no DOU de } 21 / 03 / 2020 \text { - } \\
\text { edição extra-H }\end{array}$ & $\begin{array}{l}\text { Regulamenta a Lei no } 13.979 \text {, de } 6 \text { de } \\
\text { fevereiro de } 2020 \text {, para definir os serviços } \\
\text { públicos e as atividades essenciais. }\end{array}$ \\
\hline $\begin{array}{l}\text { Resolução nº 20, de } \mathbf{2 3} \text { de março de } 2020 \\
\text { Publicada no DOU de } 25 / 03 / 2020\end{array}$ & $\begin{array}{l}\text { Dispõe sobre as medidas emergenciais } \\
\text { devido à Crise de Calamidade Pública } \\
\text { ocorrida com a pandemia do novo } \\
\text { coronavírus (Covid-19). }\end{array}$ \\
\hline $\begin{array}{l}\text { Decreto } \mathbf{n}^{\circ} \mathbf{1 0 . 2 9 2} \text {, de } \mathbf{2 5} \text { de março de } \mathbf{2 0 2 0} \\
\text { Publicado no DOU de } 26 / 03 / 2020\end{array}$ & $\begin{array}{l}\text { Altera o Decreto } n^{\circ} 10.282 \text {, de } 20 \text { de março } \\
\text { de } 2020 \text {, que regulamenta a Lei } n^{\circ} 13.979, \\
\text { de } 6 \text { de fevereiro de } 2020 \text {, para definir os } \\
\text { serviços públicos e as atividades essenciais. }\end{array}$ \\
\hline $\begin{array}{l}\text { Portaria no 117, de } 25 \text { de março de } 2020 \\
\text { Publicada no DOU de } 26 / 03 / 2020\end{array}$ & $\begin{array}{l}\text { Reconhecimento do estado de calamidade } \\
\text { pública pelo Decreto Legislativo } n^{\circ} 6 \text {, de } \\
20 \text { de março de } 2020 \text {. }\end{array}$ \\
\hline $\begin{array}{l}\text { Portaria } \mathbf{n}^{\circ} \text { 395, de } 15 \text { de abril de } 2020 \\
\text { Publicada no DOU de } 16 / 04 / 2020\end{array}$ & $\begin{array}{l}\text { Prorroga o prazo previsto no } \S 1^{\circ} \text { do art. } 1^{\circ} \text { da } \\
\text { Portaria } n^{\circ} 343 \text {, de } 17 \text { de março de } 2020 .\end{array}$ \\
\hline $\begin{array}{l}\text { Portaria } \mathbf{n}^{\mathbf{0}} \mathbf{4 7 3} \text {, de } 12 \text { de maio de } 2020 \\
\text { Publicada no DOU de } 13 / 05 / 2020\end{array}$ & $\begin{array}{l}\text { Prorroga o prazo previsto no } \S 1^{\circ} \text { do art. } 1^{\circ} \text { da } \\
\text { Portaria } n^{\circ} 343 \text {, de } 17 \text { de março de } 2020 .\end{array}$ \\
\hline
\end{tabular}

Fonte: Brasil (2020b) 
A emissão da Portaria MEC n 343, de 17 de março de 2020 (BRASIL, 2020a), foi a primeira medida concreta em relação à regulamentação de ações voltadas ao sistema federal de Ensino, cancelando as aulas presencias, por força das circunstâncias impostas pela pandemia, e determinando a adoção do Ensino remoto ou do Ensino mediado pelas Tecnologias da Informação e Comunicação (TICs), à exceção dos cursos de medicina e daqueles que requerem práticas de estágios e de laboratórios, dos demais cursos.

Diante da gravidade provocada pela explosão do número de casos da Covid-19, o MEC foi emitindo portarias, prorrogando a excepcionalidade da oferta de aulas mediadas pelas TICs, pelas universidades federais, a cada 30 dias, de forma que esta prorrogação de prazo, a conta gotas, foi mais um desafio às universidades federais, notadamente em relação à garantia de acesso e de permanência.

Segundo Dourado (2019, p.13), o atual governo tem feito duras críticas às universidades públicas, por meio de questionamentos diversos relacionados às finalidades da Educação escolar, concretizando tais questionamentos por meio da redução drástica de recursos financeiros destinados, inclusive, à Educação Superior. Como referem Ferrari e Cunha (2020), o momento atual demanda ação:

Governos marcados por ideologias pró-mercado e anti-Estado, como Alemanha, Estados Unidos e Reino Unido, para citar alguns exemplos, estão atuando com larga margem financeira. Focam na manutenção da reprodução da vida social e, assim, na preservação de empregos, empreendimentos e rendas, percebendo que o problema central não é de restrição fiscal a priori do Estado, o que não existe quando se tem a possibilidade de emitir moeda e dívida. Mas, sim, de manutenção da ordem social.

Aliás, o país está enfrentando algumas crises, no âmbito da União, situação agravada pelos 428.034 óbitos, conforme dados disponíveis, no dia 12 de maio de 2021 no portal governamental do Coronavírus/Brasil, de acordo com Brasil (2021), o que leva à grande preocupação, pois o Estado precisa, urgentemente, ser assertivo, relegando as discussões ideológicas para momento mais oportuno.

A crise sanitária e política, o negacionismo, a omissão e a ausência de um Comitê de Gestão de Crise, no Ministério da Saúde, durante mais de um ano, desde o início da pandemia, provocaram a instalação de uma Comissão Parlamentar de Inquérito (CPI), no Senado Federal, no dia 8 de abril de 2021, determinada pelo ministro do Supremo Tribunal Federal (STF), Luís Roberto Barroso, que concedeu liminar 
(decisão provisória) em ação movida pelos senadores Alessandro Vieira e Jorge Kajuru, com o objetivo de investigar as ações do governo federal, e o uso de recursos da União, por Estados e por Municípios, destinados ao enfrentamento da pandemia.

A CPI terá 90 dias de prazo para a condução dos trabalhos de investigação, podendo solicitar prorrogação, nos termos legais que a regulamentam, e, ao final, deverá emitir um Relatório, a ser encaminhado, posteriormente, após a sua aprovação, ao Ministério Público ou à Advocacia Geral da União, para as providências cabíveis.

\section{Metodologia}

$\mathrm{Na}$ linha dos objetivos que orientaram essa investigação, estruturou-se a presente pesquisa, apresentando-se, na Introdução, um quadro contendo a esquematização das medidas tomadas pelo Estado, com vistas ao enfrentamento da pandemia causada pela Covid-19, no tocante à Educação Superior. Depois, forneceu-se um panorama da situação de atividade das universidades federais, após a emissão da Portaria MEC no 343, de 17 de março de 2020 (BRASIL, 2020a) - que regulamentou a oferta de aulas utilizando meios digitais, enquanto durasse a situação de excepcionalidade - tendo por base relatórios, bancos de dados, legislação pertinente, bem como bibliografia específica, adequada a essa investigação de cunho exploratório, utilizando-se uma estratégia bibliográfico-documental, sendo que foram considerados, como amostra de dados e ponto de partida para a construção do presente estudo, os primeiros registros disponíveis no < portal. mec.gov.br/coronavirus/>, disponibilizados a partir do mês de maio de 2020 .

Em seguida, foi elaborado um breve contexto histórico relativo ao surgimento da universidade, em nosso país, e, por fim, constatou-se que a pandemia precipitou, não só as discussões relacionadas ao Ensino a distância (EaD), ao aprendizado remoto e ao uso das TICs, como também colocou em evidência que o modelo de universidade atualmente vigente, baseado na cátedra, precisará se reinventar, para se adequar às novas exigências impostas pela excepcionalidade da Covid-19.

\section{Panorama de atividades das universidades federais, durante a pandemia}

Para prestar contas das ações governamentais de enfrentamento à Covid-19, o MEC criou o <portal.mec.gov.br/coronavirus/>, transcorridos dois meses o surgimento dos primeiros casos da pandemia no Brasil. Assim, segue, no Quadro 2, o panorama geral - dados do dia 10 de maio de 2020 - das atividades nas universidades federais brasileiras, após a emissão da Portaria MEC n ${ }^{\circ} 343$, de 17 de março de 2020 (BRASIL, 2020a). 
Quadro 2 - Panorama Geral das atividades nas Ifes, após a emissão da Portaria MEC n 343/2020 - situação em 10 de maio de 2020

\begin{tabular}{|l|c|c|c|c|c|c|c|}
\hline Ifes & $\begin{array}{c}\text { Com } \\
\text { atividades } \\
\text { remotas/ } \\
\text { TICs }\end{array}$ & $\begin{array}{c}\text { Com } \\
\text { atividades } \\
\text { parciais }\end{array}$ & $\begin{array}{c}\text { Com } \\
\text { atividades } \\
\text { suspensas }\end{array}$ & $\begin{array}{c}\text { Discentes } \\
\text { matriculados } \\
\text { em Ifes }\end{array}$ & $\begin{array}{c}\text { Discentes } \\
\text { com } \\
\text { atividades } \\
\text { remotas/ } \\
\text { TICs }\end{array}$ & $\begin{array}{c}\text { Discentes } \\
\text { com } \\
\text { atividades } \\
\text { parciais }\end{array}$ & $\begin{array}{c}\text { Discentes } \\
\text { com } \\
\text { atividades } \\
\text { suspensas }\end{array}$ \\
\hline 69 & 8 & 6 & 55 & 1.123 .691 & 153.402 & 99.899 & 870.390 \\
\hline $100 \%$ & $11,6 \%$ & $8,69 \%$ & $79,71 \%$ & $100 \%$ & $13,65 \%$ & $8,90 \%$ & $77,45 \%$ \\
\hline
\end{tabular}

Fonte: Elaborado pelas autoras, baseadas no MEC (BRASIL, 2020a)

Esquematizaram-se, no Gráfico 1, os dados do Quadro 2, objetivando fornecer uma visão geral do panorama de atividades das universidades federais, em 10 de maio de 2020.

Gráfico 1 - Panorama Geral das atividades nas Ifes, após a emissão da Portaria MEC n' 343/2020 - situação em 10 de maio de 2020

Panorama Geral de atividades nas Universidades Federais Brasileiras, após a emissão da Portaria MEC na 343, de 17 de março de 2020.

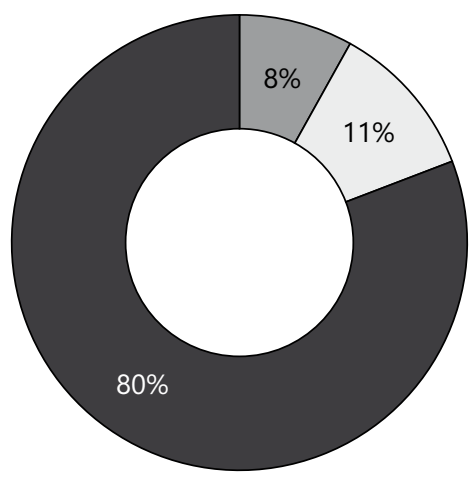

Universidades Federais em atividades remotas/TICs

Universidades Federais em atividades parciais

Universidades Federais com atividades paralisadas

Fonte: Elaborado pelas autoras, 2020, baseadas no MEC (BRASIL, 2020a)

De um contingente de 69 universidades federais, cerca de $20 \%$ estavam funcionando de forma remota, ou em regime de atividades parciais no início de maio de 2020, atendendo, dessa forma, à apenas $22,5 \%$ do contingente de discentes matriculados, o que significa que quase $80 \%$ ficaram fora das salas de aulas remotas. Esse foi um dado preocupante, pois demonstrou que, naquele momento, as universidades federais não eram capazes de cumprir o seu papel básico, que é dar acesso 
universal àqueles que procuram um Ensino Superior de qualidade. E o que dizer do panorama das universidades federais que suspenderam suas atividades por região geográfica? Vejamos o que mostra o Gráfico 2.

Gráfico 2 - IFES que suspenderam suas atividades por força da Portaria MEC $n^{\circ}$ 343/2020 - situação em 10 de maio de 2020

Universidades Federais que suspenderam suas atividades, por região geográfica

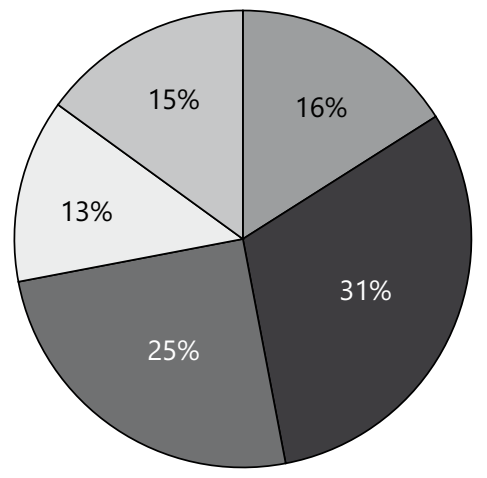

$\square$ Região Norte

$\square$ Região Nordeste

$\square$ Região Sudeste

$\square$ Região Centro Oeste

$\square$ Região Sul

Fonte: Elaborado pelas autoras, baseadas em MEC (BRASIL, 2020a)

A Região Nordeste foi a que apresentou maior índice de universidades federais com atividades suspensas - em torno de $31 \%$ - estando, em segundo lugar, para nossa surpresa, a Região Sudeste - que responde por $25 \%$ do total nacional de universidades federais - com as atividades paralisadas. As Regiões Sul, Norte e Centro-Oeste apresentaram percentuais muito próximos e cujos índices foram, separadamente, cada qual, a metade dos índices apresentados pelas regiões Nordeste e Sudeste. Disto, depreende-se que as universidades federais das Regiões Centro-Oeste, Sul e Norte tiveram maiores índices de adesão ao Ensino remoto ou às atividades em regime parcial do que aquelas localizadas nas Regiões Nordeste e Sudeste.

No âmbito dessa pesquisa, faz-se necessário alguns registros acerca do EaD em nosso país, e, neste sentido, em conformidade com alguns dados da Associação Brasileira de Educação a Distância (ABED, 2018, p. 9), em relação aos recursos utilizados como ferramentas de aprendizagem no $\mathrm{EaD}$, as teleaulas vêm em primeiro lugar. Tal cenário está detalhado no Gráfico 3. 
Gráfico 3 - Ferramentas de aprendizagem inerentes ao Ensino a distância

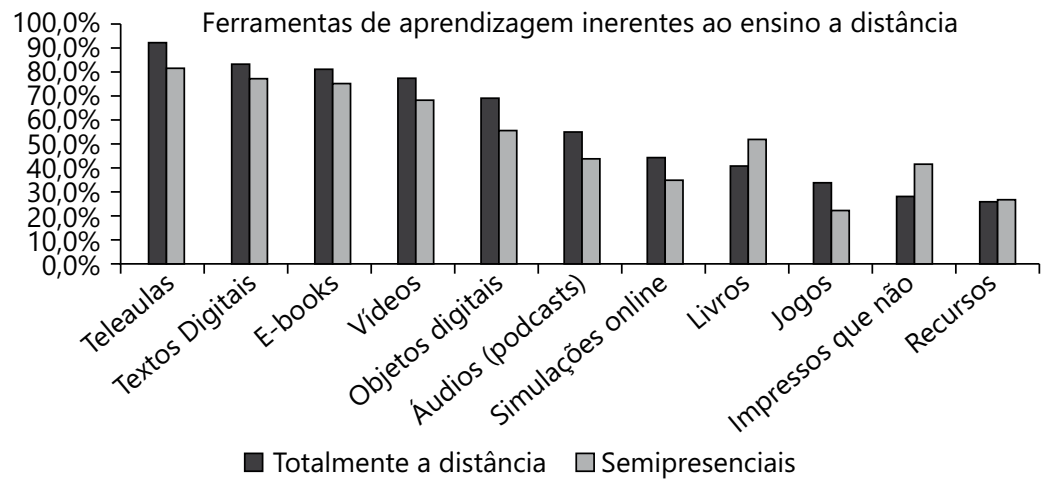

Fonte: Elaboração das autoras, baseadas em $\operatorname{ABED}(2018$, p. 11)

Para a Abed (2018, p. 9), as teleaulas aparecem como recurso pedagógico em primeiro lugar, devido a diversos fatores, destacando-se, neste caso, a tendência à humanização do ambiente on-line, o que considera como fator preponderante, a partir da constatação de que no nosso país, em certas regiões, o acesso a uma Educação de melhor qualidade só ocorre com a ajuda da tecnologia. Os textos digitais aparecem como recurso de aprendizagem em $83,7 \%$ de cursos totalmente $\mathrm{EaD}$ e em 78,2\% em cursos semipresenciais, ressaltando que o recurso foi dos primeiros formatos do Ensino presencial que se adaptou ao ambiente digital, pois exige pouca habilidade técnica e ocupa menos espaço e banda.

Conforme dados da Abed (2018, p. 9), o terceiro recurso pedagógico do EaD são os e-books, que aparecem com $81,5 \%$ e 75,5\%, em cursos totalmente a distância e em cursos semipresenciais, respectivamente. Os vídeos, que não sejam do estilo de teleaulas, são o recurso pedagógico que aparece como quarto colocado, respondendo por um percentual de 77,8\%, nos cursos totalmente a distância e $69,1 \%$ nos cursos semipresenciais. A Abed $(2018$, p. 10) registra que os objetos digitais de aprendizagem, que permitem que se criem aulas dinâmicas, é o quinto recurso pedagógico que aparece nas estatísticas do Censo de 2018. Neste sentido,

Existem vários repositórios que disponibilizam esses recursos, até mesmo o portal do Ministério da Educação (MEC), como a Rede Interativa Virtual de Educação (RIVED). Esses objetos são recursos que permitem a criação de aulas dinâmicas customizadas, sendo que o autor do curso pode definir a quantidade e a ordem que atenda os objetivos do seu curso (ABED, 2018, p. 10). 
Já os livros impressos têm registrado queda, como recurso didático na modalidade EaD, sendo substituídos por recursos mais sofisticados, como podcasts, por exemplo, sendo, no entanto, um recurso pedagógico que aparece mais em cursos semipresenciais. A Abed (2018, p. 10), ressalta que os jogos eletrônicos favorecem a aquisição de habilidades mais complexas - enquanto recurso pedagógico - tais como a aquisição de pensamento estratégico, capacidade de planejamento e visão colaborativa, ferramentas importantes para a Educação deste século XXI. Já os recursos adaptativos ainda estão em fase de desenvolvimento. "Outros recursos que despontam no cenário internacional incluem a inteligência artificial, a realidade virtual e aumentada (realidade mista), a blockchain e os assistentes virtuais" (ABED, 2018, p. 10).

É preciso deixar clara a diferença que existe entre o Ensino semipresencial e o EaD. O Ensino semipresencial oferece apenas uma parte do curso na modalidade presencial, podendo ter sua origem em cursos presenciais ou em cursos a distância, sendo que quando são originários de cursos presenciais, nem todas as disciplinas são ofertadas nessa modalidade e os encontros presenciais ocorrem na própria instituição de ensino. Já os semipresenciais, originários de cursos $\mathrm{EaD}$, necessitam de um polo de apoio presencial, para os encontros, e precisa atender a algumas especificidades. De acordo com a Abed (2018, p. 70) "os conteúdos curriculares têm que estar corretos e atualizados, sendo necessário que os tutores e os docentes sejam qualificados e as metodologias devem ser eficazes no processo de aprendizagem".

O Gráfico 4 apresenta os valores percentuais de utilização de internet, em nosso país, em conformidade com a Pnad TIC do $4^{\circ}$ trimestre de 2018, realizada pelo Instituto Brasileiro de Geografia e Estatística (IBGE).

Gráfico 4 - Valores percentuais de utilização de internet, em domicílios particulares permanentes, por região $-4^{\circ}$ trimestre de 2018

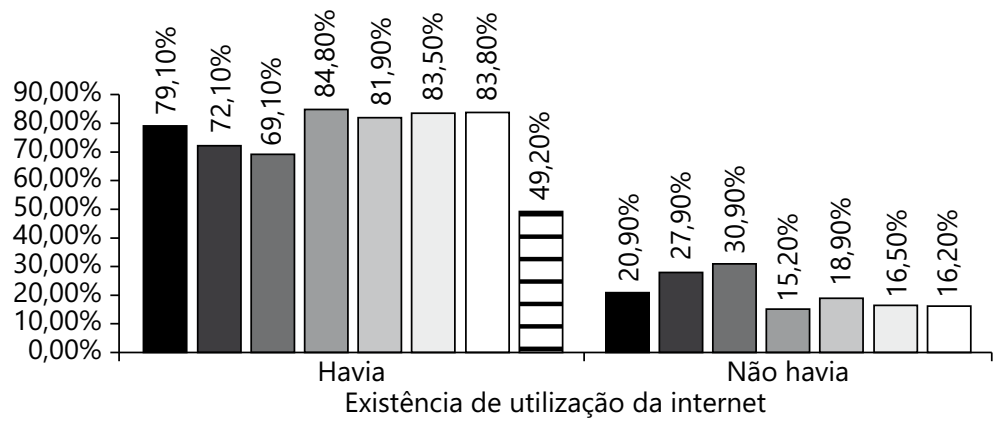

\begin{tabular}{|c|c|c|c|}
\hline & $\begin{array}{l}\square \text { Região Norte } \\
\square \text { Região Centro Oeste }\end{array}$ & $\square$ Região Nordeste & $\square$ Região Sudeste \\
\hline
\end{tabular}

Fonte: Elaborado pelas autoras, baseadas em IBGE (2018) 
O Gráfico 4 demonstrou que, apesar da difusão do uso da internet, a região Nordeste foi a que apresentou o menor índice de acesso, em torno de $69,1 \%$, inferior à média nacional, apresentando um déficit de acesso ao serviço em torno de 30,9\%. Por outro lado, as Regiões Sudeste e Centro-Oeste apresentaram percentuais de acesso bastante próximos: $84,8 \%$ e $83,5 \%$, respectivamente, maiores do que a média nacional, que é de $79,1 \%$. Ainda, constatou-se que um contingente de $20,9 \%$ dos lares brasileiros não tem acesso à internet.

Partindo-se da constatação da suspensão das atividades em cerca de $80 \%$ das universidades públicas federais no início da pandemia, vejamos os dados, sob a ótica relacionada ao contingente de discentes que tiveram suas atividades paralisadas, no período, esquematizados no Gráfico 5.

Gráfico 5 - Discentes com atividades suspensas, por região geográfica - situação em maio de 2021

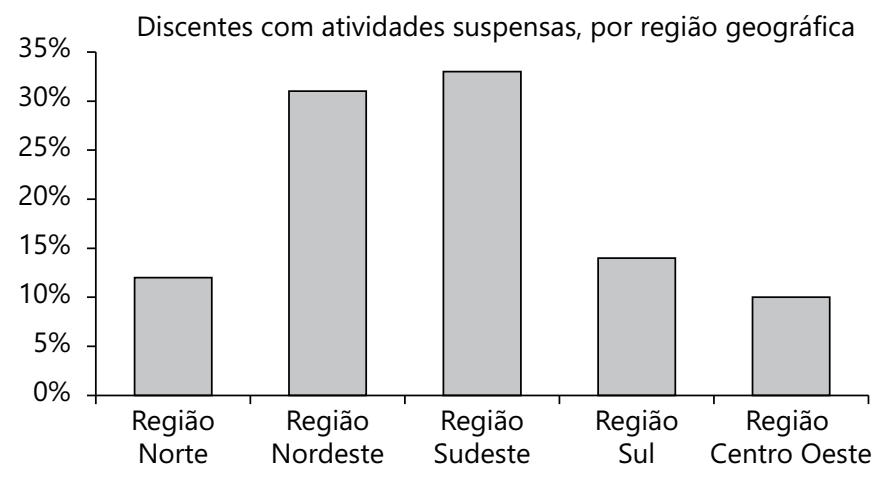

Fonte: Elaborado pelas autoras, baseadas em MEC (BRASIL, 2020a)

A Região Sudeste apresentou o maior índice de discentes com atividades paralisadas, em torno de 33\%, muito próximo ao índice de alunos sem atividades da Região Nordeste, que foi de $31 \%$. O que se constatou, até o momento, foi que não há condições de retorno às aulas presenciais, transcorrido mais de um ano do início da pandemia - apesar de iniciativas em contrário, em alguns Estados, no Ensino Fundamental e nas faculdades da iniciativa privada - porque o Ensino presencial aglomera e o novo coronavírus tem, na aglomeração de pessoas, o seu maior aliado na disseminação do contágio. Tal fato, agravado pela desorganização e pelo atraso em relação à execução do cronograma de vacinação, torna o retorno às atividades de Ensino presenciais uma temeridade. Como afirmam CASTIONI et al. (2021, p. 405): 
Os desafios que advêm do enfrentamento da pandemia da Covid-19 obrigaram as instituições educacionais a repensarem suas atividades e a sua relação com as diversas tecnologias de informação e de comunicação, a formação para uma nova cidadania digital e as suas próprias estratégias de governança.

Por fim, o MEC criou um Protocolo de Biossegurança para retorno às atividades nas instituições federais de ensino, em 04 de maio de 2021, (BRASIL, 2021), contendo recomendações que demandam a aquisição de insumos diversos, e, ao mesmo tempo, de acordo com a Andifes (2021), as universidades federais sofreram um corte no orçamento de custeio, de mais de $18 \%$, sendo que o acumulado, desde o ano de 2019, soma $25 \%$ do orçamento das IFES. Segundo a Andifes (2021), é consenso de que deve haver negociações para o retorno às atividades presenciais, precedida de uma discussão que viabilize o retorno de recursos, de, pelo menos, $20 \%$ do orçamento, sob pena de descontinuidade de muitas políticas públicas implementadas, direcionadas à ampliação da oferta de acesso e de inclusão ao Ensino Superior.

\section{O surgimento da universidade no Brasil}

Apesar de a Proclamação da República ter ocorrido no ano de 1889, só em 1891 foi promulgada a segunda Constituição Brasileira. Machado $(2009$, p. 89) diz que, no período em que a Constituição de 1891 vigorou - de 1891 a 1934 - ocorreram as seguintes reformas direcionadas ao Ensino Superior: Reforma Epitácio Pessoa (1901), Reforma Rivadávia Correia (1911), Reforma Carlos Maximiliano (1915), Reforma Rocha Vaz (1925) e o Estatuto das Universidades Brasileiras, de autoria de Francisco Campos (1931).

No final de 1930, foi criado o Ministério da Educação e Saúde Pública, e Francisco Campos foi seu primeiro titular. Responsável pela criação do Conselho Nacional de Educação (CNE), instituiu, por meio do Decreto n ${ }^{\circ}$ 19.851, em 11 de abril de 1931, a Reforma do Ensino Superior, conhecida como o Estatuto das Universidades Brasileiras. Na proposta de Fernando de Azevedo, o Ensino Superior estaria intimamente articulado ao Ensino Secundário, por meio de uma formação geral e da disciplina intelectual, como preparação para o ingresso no Ensino Superior, e a formação, em escolas superiores, de professores para as escolas secundárias. Cunha (1975) informa que, para Fernando Azevedo, era na universalidade que se podia ter a certeza do progresso, e utilizou esse argumento como condição para organização delas.

Instituição essencialmente cultural e educativa, os centros universitários não servem apenas às mais altas necessidades 
espirituais da nação. Se considerarmos, de um lado, a influência cada vez mais pronunciada, das ciências na direção das sociedades modernas e, por outro lado, a complexidade crescente de que se revestem os problemas técnicos que os governos são obrigados a enfrentar, compreende-se a "função política" que desempenham os institutos de cultura superior, onde se terão de formar as nossas classes dirigentes (p. 232).

No Quadro 3, estão elencadas as principais características do Estatuto das Universidades Brasileiras, de acordo com Cunha (1975, p. 263-266).

Quadro 3 - Principais características do Estatuto das Universidades Brasileiras

O Estatuto criou um modelo único - com ressalvas para certas variações regionais, que seriam submetidas ao crivo do Ministério da Educação; um dos traços da política educacional autoritária é a negação da pluralidade e da divergência, consideradas inimigas da ordem.

b) Autonomia didática e administrativa restritas - a escolha dos membros do Conselho Técnico-Administrativo (CTA) de cada instituto, dos Reitores e Diretores foi concebida com o objetivo de "fazer o poder do Estado penetrar até as primeiras instâncias da organização do ensino. " (CUNHA, 1975, p.263). A forma como o CTA foi constituído permitiu a diminuição do poder da congregação e o CTA passou a assumir várias atribuições, antes de competência da congregação, tais como rever os programas de Ensino das disciplinas, autorizar a realização dos cursos previstos pelo regulamento, fixar o número de vagas de cada turma, entre outras ações.

c) Organização da comunidade acadêmica baseada em critérios corporativos - de um lado, a Associação dos Professores Universitários, e, de outro, os Diretórios dos Estudantes. Há todo um detalhamento em relação à constituição destas duas entidades representativas, que regulamenta, em detalhes, composição, atribuições, estatuto, código de ética... ao final, estabelecia que se esperavam "medidas de previdência e benemerência" como resultado do diálogo entre essas duas entidades representativas.

d) A universidade foi concebida para ser um centro difusor de ideologia - a ideologia da Era Vargas, que mantinha controle rígido, notadamente às ideias liberais no setor educacional.

Fonte: Elaborado pelas autoras, baseadas em Cunha (1975, p. 263-266)

Apesar da rigidez, percebeu-se no Estatuto das Universidades Brasileiras - ainda hoje em vigor - alguma flexibilidade em relação ao regime didático-administrativo, em relação aos mandatos universitários e aos cursos. Surgia o embrião de parcerias, que hoje são fato consolidado, por meio da celebração de convênios com institutos e serviços técnicos ou científicos, entre outros, fato inédito, até então.

Segundo Cunha (2014, p. 362), a reforma do Ensino Superior, que ocorreu durante a Ditadura Militar, favoreceu a criação da Universidade, da forma como a conhecemos hoje, visto que, até então, existiam faculdades isoladas, sem o devido regramento 
administrativo e acadêmico. Ocorreu uma grande contradição em relação a esse período histórico, pois foi por causa da repressão do regime político da Ditadura - com respaldo nos Atos Institucionais e da Constituição de 1967 - que o Ensino Superior deu um passo em direção à evolução, extinguindo o antigo regime de cátedras e modernizando a organização acadêmica e administrativa nas IFES.

De maneira geral, pode-se dizer que o objetivo da criação do Estatuto das Universidades Federais, foi - além da sistematização e da padronização desse nível de Ensino - promover a modernização, apesar de ser uma medida educacional autoritária, devido ao viés centralizador - sua característica mais marcante - o que nos leva a ressaltar que, mesmo atualmente, a autonomia didático-administrativa no Ensino Superior federal é relativa, pois como as IFES são mantidas pela União, precisam se adequar às normas e às políticas públicas educacionais - instituídas pelo Estado - para que tenham direito aos recursos a elas destinados, em conformidade com o cumprimento de certas exigências, desde o advento do Estado Gerencialista, que vincula a liberação de recursos ao cumprimento de metas.

As diversas tentativas de encontrar um modelo próprio de universidade no Brasil parecem não ter resistido à forte influência das concepções mais tradicionais que fundamentaram o surgimento desse tipo de instituição. Sua identidade, portanto, envolve uma associação de concepções e pode explicar, em parte, os embates que se travam no interior de suas escolas e suas faculdades, quando se trata de defender o papel da universidade na sociedade atual (SOUZA et al., 2013, p. 231).

\section{Uma nova instituição para um novo tempo}

Dourado (2019, p. 14-15), lembra que, entre os muitos deveres do Estado, destaca-se o do estabelecimento do Plano Nacional de Educação (PNE), de vigência decenal, que tem o objetivo de estabelecer diretrizes, objetivos, metas e estratégias, visando a manutenção e o desenvolvimento do ensino, em seus diversos níveis, etapas e modalidades, o que o atual governo federal questiona, inclusive reduzindo os recursos destinados à Educação. Tais questionamentos, somados ao conhecimento científico e afins e referentes ao papel e às restrições à autonomia universitária, concretizadas em forma de decretos, de cortes orçamentários e de proposta de nova governança e do projeto "Future-se", colocam em risco o pluralismo de ideias e de concepções pedagógicas, a autonomia didático-científica, administrativa e de gestão financeira e patrimonial, entre tantas outras conquistas asseguradas pela Constituição Federal de 1988. Como refere DOURADO (2019, p. 13):

É nesse cenário que se situam os desafios para a Educação nacional no que concerne à garantia de acesso e permanência com qualidade 
social, num estado com enorme dívida social no campo educacional e que apresenta riscos no tocante à manutenção do Estado Democrático de Direito, como preconizado na Constituição Federal de 1988.

A Meta 12 do PNE para o decêncio 2014/2024 é elevar a taxa bruta de matrícula na Educação Superior para 50\% e a taxa líquida para 33\% da população de 18 a 24 anos, assegurada a qualidade da oferta e da expansão para, pelo menos, $40 \%$ das novas matrículas no segmento público, conforme o Instituto Nacional de Estudos e Pesquisas Educacionais Anísio Teixeira (INEP, 2015, p. 209). Pelos dados analisados, constatou-se que persiste a desigualdade histórica no acesso à Educação Superior entre as diferentes regiões geográficas, entre os diferentes grupos populacionais e entre os diferentes estratos socioeconômicos.

Este é um grande desafio para as universidades federais e para o Estado, levando-se em consideração que o ano de 2020 será lembrado como o ano em que as universidades federais viveram a pior crise de que se tem notícia, cuja face mais cruel foi a constatação do despreparo de todos (Estado e universidades federais), expondo a necessidade de apoio, diálogo e cooperação, entre todos os envolvidos, o que, infelizmente, ainda está em construção.

Santos (2018, p. 588-592), faz reflexões complexas a respeito da ideia da universidade moderna, referindo-se a uma mudança de paradigma, afirmando, entre outras coisas, que a universidade será, em breve, uma instituição do passado e, que, para ser capaz de se pautar pela ciência moderna deverá transformar os seus processos de investigação, de Ensino e de extensão, e, nesse sentido, o verdadeiro mercado para o saber universitário reside no futuro, com o que estamos plenamente de acordo. Segundo Santos (2018, p. 592),

O grande perigo para a universidade nas próximas décadas é o de os dirigentes universitários se limitarem a liderar inércias. As grandes transformações não podem ser postas de parte só porque a universidade criou a seu respeito o mito da irreformalidade. É de prever que a curto prazo a crise institucional monopolize o esforço reformista.

A universidade pública deverá, no dizer de Ristoff (2020), assumir papel de liderança em relação ao enfrentamento dos desafios da atualidade, referentes à segurança alimentar, a mudanças climáticas e à saúde pública, entre outros, cabendo ao Estado investir fortemente para viabilizar tais ações, lembrando, ainda, que o conhecimento necessita, para avançar, de investimento público, decisivo e 
continuado e, para o autor, o campus do futuro não será um lugar, mas uma rede, que fará parte de inúmeras outras redes já espalhadas mundo afora.

\section{Considerações finais}

Diante das medidas tomadas pelo Estado, em relação à Educação Superior, foi perceptível a inércia e a incapacidade de fornecer respostas assertivas e de estabelecer rotinas e procedimentos padronizados que fossem capazes de evitar que quase um milhão de estudantes, matriculados nas universidades federais, ficassem com suas atividades acadêmicas paralisadas, em um primeiro momento. O fato de, a cada 30 dias, o MEC emitir Portarias que prorrogavam o prazo da situação de excepcionalidade, sem uma diretriz capaz de dar confiança, tanto às universidades públicas quanto aos mais de 800 mil estudantes com atividades suspensas, provocou, além de incertezas relacionadas às atividades acadêmicas, inseguranças diversas, relacionadas, principalmente, a um futuro difícil de ser previsto e planejado, pois faltam normativas legais que assegurem respaldo e capacidade de planejamento para o período de vácuo imposto pela suspensão das atividades presenciais.

Os conflitos foram inevitáveis e a inércia foi o resultado da negação, da falta de diálogo entre as partes envolvidas e da incapacidade de todos em lidar com a calamidade, processo agravado pela ausência de lideranças capazes de mobilizar esforços conjuntos para o enfrentamento da situação. Todos estão passando pela mesma situação, mas a cegueira causada pelas intermináveis discussões ideológicas e pelo negacionismo serviu, a uns e outros, como desculpa para a omissão e para a ausência de propostas de soluções viáveis diante da gravidade da situação. Todos perdem, as crises se aprofundam, deixando vulneráveis os entes sociais envolvidos e, nesse processo permeado por diversas crises de identidade e de autonomia, a opinião pública julga e as (des)informações se propagam, em progressão geométrica, à semelhança do vírus. A quem serve tal tipo de coisa?

Sabe-se que as universidades federais têm, no convívio harmônico da diversidade de pensamentos, de orientações filosóficas e da pluralidade de ideias, um de seus traços mais marcantes, o que acaba por replicar as relações contraditórias e conflituosas próprias de ambientes multiculturais. Tal peculiaridade no ambiente universitário, por um lado, aproxima culturas, pessoas, visões e comportamentos, e, por outro, torna o ambiente extremamente desafiador, cheio de contradições e de resistência, de forma que o Ensino presencial está vivenciando uma crise de identidade, e uma grande contradição na medida em que, mesmo que os dados apontem para uma alarmante exclusão digital e tecnológica dos discentes das universidades federais, em torno de 77,40\%, é impossível ignorar a existência 
de ferramentas e de plataformas interativas nos meios digitais, adequadas à viabilização do EaD, tais como o Skype, Zoom Cloud Meetings, Hangouts Meet, Cisco Webex, Moodle, e a mais rudimentar de todas, o e-mail, passando pelas interações favorecidas pelas redes sociais, como o WhatsApp.

Isto posto, pergunta-se: por que apesar dos recursos investidos no sistema Universidade Aberta do Brasil (UAB), as universidades federais se mostraram incapazes de adotar a Educação a Distância, excluindo quase um milhão de estudantes, em todo o país, das atividades de ensino? Que dificuldade há em se adotar as teleaulas, pelo menos durante a pandemia? Qual a justificativa para não se disponibilizar, por e-mail, capítulos de livros e outros materiais didáticos, em formato digital? Por que não utilizar o Youtube como plataforma digital, disponibilizando vídeos didático pedagógicos? O que impede as universidades federais de elaborarem plataformas de simulações on-line, destinadas ao aprendizado remoto? Por que não usar as simulações dos jogos eletrônicos como recurso pedagógico no Ensino remoto?

Diante de tantos questionamentos, temos algumas hipóteses. Constatamos que as universidades, com suas estruturas extremamente hierarquizadas, tornaram-se instituições com alguma dificuldade em planejar, por isso, também lhes falta o preparo para administrar riscos ou calamidades, situação que se agrava devido ao modelo organizacional em que se encontram fundamentadas, marcado por uma pesada burocracia e pela submissão à regramentos jurídicos, por sua vez, mais rígidos e inflexíveis que os que criaram, por meio de seus colegiados e de inúmeras estruturas características do modelo atual de universidade pública federal, criado na década de 1930.

Aliás, a dificuldade em administrar calamidades estende-se também ao Estado, e, em particular, ao MEC, que, só no mês de maio de 2021, estabeleceu um protocolo de biossegurança, recomendando que seja utilizado, por todas as universidades federais e institutos que integram o Ensino Superior público, e que, para ser viabilizado e implementado, necessitará da aquisição de insumos, o que implica em realização de licitações para tal, apesar de as universidades federais terem sofrido um corte no orçamento de custeio, de mais de $18 \%$, no exercício financeiro de 2021.

Sabe-se que o Ensino remoto é mais desafiador para o docente, inclusive, porque nessa modalidade não é possível replicar os horários do Ensino presencial. A dinâmica de aprendizado é mais complexa, e tal novidade causa, primeiro, resistência, e, em seguida, negação, porque, o que ocorre é que os docentes, 
em sua maioria, têm pouca intimidade com as TICs, necessitando, portanto, de capacitação. Entretanto, é mais fácil criticar, opor resistência e apontar dificuldades do que propor soluções concretas.

Pelos dados dessa pesquisa, percebeu-se que o Ensino remoto não é tão difícil de ser implementado, bastando alguma boa vontade dos entes envolvidos, e a abertura de créditos específicos, por parte do Estado, destinados à modernização dos parques tecnológicos das universidades federais. De uma forma ou outra, o futuro das universidades federais está em adotar um modelo de Ensino mediado pela tecnologia, sendo capaz, ela própria, de se transformar em uma nova instituição, para um novo tempo, no período pós-pandemia. As ferramentas para tal processo, já existem há algum tempo, necessitando, para serem implementadas, do estabelecimento de um diálogo entre o Estado e as universidades públicas, visando a sobrevivência do patrimônio educacional das universidades federais. No entanto, este diálogo, infelizmente, encontra-se estagnado, por diversos motivos.

Nada mais será como antes. Os paradigmas, as crenças, os dogmas, a Educação, a saúde pública, a economia, as relações de trabalho, as interações e as subjetividades próprias das relações pessoais, as políticas de Estado, bem como as consequências e os impactos impostos pelo isolamento social, foram a causa de um cruel choque de realidade, que expôs toda a fragilidade do ser humano e das instituições que se acreditavam inabaláveis. 


\title{
The challenges of the public university in the Covid-19 post-pandemic: The Brazilian case
}

\begin{abstract}
The purpose of this article is to reflect on the challenges of the public university model in the Covid-19 post-pandemic, based on data made available by the Portal of the Ministry of Education of Brazil. An exploratory methodology was used, with a qualitative approach and a bibliographic-documental strategy. The public university profile that emerged from the data suggests the need for a change in the institutional and organizational model, which currently accommodates the university. It is imperative that the university reinvents itself, that it becomes a new institution, endowed with current, flexible management models and that favors adjustments, since such functionalities are better suited to organizational dynamics and risk management.
\end{abstract}

Keywords: MEC/Coronavirus Portal. Pandemic. Public University.

\section{Los desafíos de la universidad pública pandémica post-Covid-19: el caso brasileño}

\section{Resumen}

El propósito de este artículo es reflexionar sobre los desafios de la universidad pública pandémica post-Covid-19, con base en datos proporcionados por el Portal del Ministerio de Educación en Brasil. Se utilizó una metodología exploratoria, con enfoque cualitativo y estrategia bibliográfico-documental. Se encontró que el perfil de la universidad pública que surgió de los datos sugiere la necesidad de un cambio en el modelo institucional y organizacional que actualmente acomoda a la universidad. Es imperativo que la universidad se reinvente, que se convierta en una nueva institución, dotada de modelos de gestión actuales, flexibles y que favorezcan los ajustes, ya que dichas funcionalidades se adecuan mejor a la dinámica organizacional y a la gestión de riesgos.

Palabras clave: Portal MEC/Coronavirus. Pandemia. Universidad Pública. 


\section{Referências}

ASSOCIAÇÃO BRASILEIRA DE EDUCAÇÃO A DISTÂNCIA - ABED. Censo EAD.BR 2018: relatório analítico de aprendizagem a distância no Brasil. São Paulo, 2018. Disponível em: http://www.abed.org.br/site/pt/midiateca/ censo_ead/1644/2019/10/censoeadbr__2018/2019. Acesso em: 24 jun. 2021.

ASSOCIAÇÃO NACIONAL DOS DIRIGENTES DAS INSTITUIÇÕES FEDERAIS DE ENSINO SUPERIOR - ANDIFES. Corte de mais de 18\% no orçamento das universidades federais em 2021, poderá inviabilizar ensino, diz entidade. Brasília, DF, 2021. Disponível em: https://www.andifes.org.br/?p=88267. Acesso em: 13 maio 2021.

BRASIL. Legislação Covid-19. Brasília, DF, 2020b. Disponível em: http://www. planalto.gov.br/CCIVIL_03/Portaria/quadro_portaria.htm. Acesso em: 3 jul. 2020.

BRASI. Ministério da Educação. Portaria n 343, de 17 de março de 2020a. Diário Oficial da União, Brasília, DF, 18 mar. 2020.

BRASIL. Ministério da Educação. Protocolo de Biossegurança para retorno das atividades nas Instituições Federais de Ensino. 2021. Disponível em: https://app. powerbi.com/view?r=eyJrIjoiYzIxYTYxOTUtZGM3OC00MWQ4LThiZTgtZDE5 YTUzN2UwMTRIIiwidCI6IjllNjgyMzU5LWQxMjgtNGVkYi1iYjU4LTgyYjJ hMTUzNDBmZiJ9. Acesso em: 12 maio. 2021.

CASTIONI, R. et al. Universidades federais na pandemia da Covid-19: acesso discente à internet e ensino remoto emergencial. Ensaio: Avaliação e políticas públicas em educação, Rio de Janeiro, v. 29, n. 111, p. 399-419, abr./jun. 2021. https://doi.org/10.1590/S0104-40362021002903108

CAVALCANTI, L. M. R.; GUERRA, M. G. G. V. Diagnóstico Institucional da Universidade Federal da Paraíba a partir da Análise SWOT. Revista Meta: Avaliação, Rio de Janeiro, v. 11, n. 33, p. 694-718, set./dez. 2019. https://doi.org/10.22347/2175-2753v11i33.2270

CUNHA, L. A. Educação e desenvolvimento social no Brasil. Rio de Janeiro: Francisco Alves, 1975.

CUNHA,L.A. Olegado da ditadura para a educação brasileira. Educação e Sociedade, v. 35, n.127, p. 357-377, abr.jun, 2014. https://doi.org/10.1590/S0101-73302014000200002 
DOURADO, L. F. Estado, educação e democracia no Brasil: retrocessos e resistências. Educação \& Sociedade, Campinas, v. 40, e0224639, 2019. https://doi.org/10.1590/ES0101-73302019224639

FERRARI, A.; CUNHA, A. M. A pandemia do Covid-19 e o isolamento social: saúde versus economia. Porto Alegre: Faculdade de Ciências Econômicas da UFRGS, 20 mar. 2020. Disponível em: https://www.ufrgs.br/fce/a-pandemia-do-covid19-e-o-isolamento-social-saude-versus-economia/\#_ftnref5 Acesso em: 3 jun. 2020.

INSTITUTO BRASILEIRO DE GEOGRAFIA E ESTATÍSTICA - IBGE. Pesquisa nacional por amostra de domicílios contínua - PNAD Contínua 2018. Disponível em: https://ftp.ibge.gov.br/Trabalho_e_Rendimento/Pesquisa_Nacional_ por_Amostra_de_Domicilios_continua/Anual/Acesso_Internet_Televisao_e_ Posse_Telefone_Movel_2018/Analise_dos_resultados_TIC_2018.pdf. Acesso em: 18 maio 2020.

INSTITUTO NACIONAL DE ESTUDOS E PESQUISAS EDUCACIONAIS ANÍSIO TEIXEIRA - INEP. Plano Nacional de Educação PNE 2014-2024: linha de base. Brasília, DF, 2015.

MACHADO, M. C. G. Manifesto dos Pioneiros da Educação Nova (1932) e a construção do sistema nacional de ensino do Brasil. In: ROSSI, E. R.; RODRIGUES, E.; NEVES, F. M. (orgs.). Fundamentos históricos da educação no Brasil. 2. ed. Ver. Ampl. Maringá: EDUEM, 2009. p.103-119. Disponível em: https://www.unijales.edu.br/library/downebook/id:848. Acesso em: 12 maio 2021

MINISTÉRIO DA EDUCAÇÃO. Portaria nº 343, de 17 de março de 2020. Brasília: MEC, 2020. Disponível em: https://www.semesp.org.br/legislacao/ portaria-no-343-de-17-de-marco-de-2020/. Acesso em: 23 jul. 2021.

OLIVEIRA, J. B. A.; GOMES, M.; BARCELLOS, T. A Covid-19 e a volta às aulas: ouvindo as evidências. Ensaio: Avaliação de Políticas Públicas em Educação, Rio de Janeiro, v. 28, n. 108, p. 555-578, jul./set. 2020. https://doi.org/10.1590/S0104-40362020002802885

RISTOFF, D. I. A caminho da nuvem: impactos da pandemia na educação. Educa 2022. 7 abr. 2020. Disponível em: https://www.educa2022.com/post/a-ca minho-da-nuvem-impactos-da-pandemia-na-educa $\% \mathrm{C} 3 \% \mathrm{~A} 7 \% \mathrm{C} 3 \% \mathrm{~A} 3 \mathrm{o}$. Acesso em: 24 jul. 2020. 
SANTOS, B. S. Construindo as Epistemologias do Sul: antologia essencial. Buenos Aires: CLACSO, 2018. V. 1: Para um pensamento alternativo de alternativas Disponível em: http://biblioteca.clacso.edu.ar/clacso/se/20181203044407/ Antologia_Boaventura_PT1.pdf. Acesso em: 24 jul. 2020.

SOUZA, J. A. S. et al. Concepções de Universidade no Brasil: uma análise a partir da missão das universidades públicas federais brasileiras e dos modelos de universidade. Revista GUAL, Florianópolis, v. 6, n. 4 (ed. Esp.), p. 216-233, 2013. https://doi.org/10.5007/1983-4535.2013v6n4p216

\section{Informações sobre as autoras}

Lourdes Maria Rodrigues Cavalcanti: Doutoranda no Programa de Pós-Graduação em Educação pela Universidade Federal da Paraíba. Técnica Administrativa (Assistente em Administração) da mesma universidade. Contato: lourdesrcavalcanti@gmail.com

(iD) https://orcid.org/0000-0002-1659-0821

Maria das Graças Gonçalves Vieira Guerra: Pós-Doutorado pela Universidade do Porto - Portugal, Doutorado em Educação. Professora Associada III do Centro de Educação da Universidade Federal da Paraíba, Professora dos Programas de Pós-Graduação em Educação da Universidade Federal da Paraíba.Contato: gracinhavieira@yahoo.com.br (iD) http://orcid.org/0000-0002-6943-0338 